Proceedings of the 11th Polish-Japanese Joint Seminar on Micro and Nano Analysis, Gniew, September 11-14, 2016

\title{
Microstructure of Small Amount of TM Added Al-Mg-Si Alloys with Two-Step Ageing
}

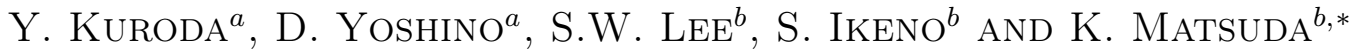 \\ ${ }^{a}$ Graduate School of Science and Engineering for Education, University of Toyama, Japan \\ ${ }^{b}$ Graduate School of Science and Engineering for Research, University of Toyama, Japan
}

\begin{abstract}
Traditionally, $\mathrm{Al}-\mathrm{Mg}-\mathrm{Si}$ alloys are strengthened by dispersed small particles and they have medium strength with good formability. It is well known that alloying elements on $\mathrm{Al}-\mathrm{Mg}-\mathrm{Si}$ alloys (e.g. $\mathrm{Cu}$ ) can improve mechanical properties because $\mathrm{Cu}$ can alter precipitation sequence. In this research, we investigated the effect of transition metals (TM) on $\mathrm{Al}-1.06 \mathrm{at} . \% \mathrm{MgSi}-\mathrm{TM}$ alloys through single- and two-step ageing. Mechanical property and microstructure observation were conducted by micro Vickers hardness measurement and transmission electron microscopy.
\end{abstract}

DOI: 10.12693/APhysPolA.131.1373

PACS/topics: 81.40.Cd, 68.37.Lp

\section{Introduction}

$\mathrm{Al}-\mathrm{Mg}-\mathrm{Si}$ system alloys have been used widely in industries as structural materials and it is well known that additional alloying elements on $\mathrm{Al}-\mathrm{Mg}-\mathrm{Si}$ alloys can increase mechanical properties. In our previous work, $\mathrm{Al}-$ $0.70 \mathrm{Mg}-0.35 \mathrm{Si}-0.2 \mathrm{Mn}$ (at.\%) alloy decreased peak hardness compared with the base alloy ( $\mathrm{Al}-1.06$ at. $\% \mathrm{Mg}_{2} \mathrm{Si}$ ) because it formed dispersoids of AlMnSi ternary system during ageing treatment. Consequently, amount of Si in $\mathrm{Al}$ matrix decreased and it resulted in weakness of agehardenability [1, 2]. However, small amount of Mn added $\mathrm{Al}-\mathrm{Mg}-\mathrm{Si}(\mathrm{Mn}<0.1$ at.\%) alloy increased the level of peak hardness without forming dispersoids. The aim of this work is to understand the effect of TMs (1) on mechanical properties and (2) on precipitation behavior.

\section{Experimental}

Four kinds of alloys were fabricated by casting to investigate the effect of TMs addition on precipitation behavior of $\mathrm{Al}-\mathrm{Mg}-\mathrm{Si}$ alloys. The chemical compositions of all alloys are shown in Table I. After casting, the alloys were homogenized at $848 \mathrm{~K}$ for $36 \mathrm{ks}$ in air atmosphere furnace, quenched into iced water. Then, the specimens were conducted solution treatment at $848 \mathrm{~K}$ for $3.6 \mathrm{ks}$ in air atmosphere furnace, quenched into iced water. Singlestep ageing was carried out at $473 \mathrm{~K}$. Two-step ageing was conducted at $298 \mathrm{~K}$ or $343 \mathrm{~K}$ for $60 \mathrm{ks}$ as pre-ageing and then, samples subjected to ageing at $473 \mathrm{~K}$. Micro Vickers hardness measurement was conducted on mirrorlike polished surface using a load of $0.98 \mathrm{~N}$ for $15 \mathrm{~s}$ of duration time. Samples were ground to a thickness of $0.07 \mathrm{~mm}$ and punched out with $3 \mathrm{~mm}$ diameter, then

*corresponding author; e-mail: ikenolab@eng.u-toyama.ac.jp thinned using a twin-jet electro-polishing facility in a solution of 33 vol. $\% \mathrm{HNO}_{3}$ and 67 vol. $\% \mathrm{CH}_{3} \mathrm{OH}$ at $258 \mathrm{~K}$ with an application of $13.5 \mathrm{~V}$. Microstructure observation was conducted by using a TOPCON 002B transmission electron microscope (TEM) operating at $120 \mathrm{kV}$ to avoid damaging to samples by electron beam.

Chemical composition of all alloys (at.\%).

TABLE I

\begin{tabular}{c|c|c|c|c|c|c|c|c}
\hline \hline Alloy & $\mathrm{Mg}$ & $\mathrm{Si}$ & $\mathrm{Ni}$ & $\mathrm{Co}$ & $\mathrm{V}$ & $\mathrm{Al}$ & $\mathrm{Mg}+\mathrm{Si}$ & $\mathrm{Mg} / \mathrm{Si}$ \\
\hline base & 0.71 & 0.37 & - & - & - & bal. & 1.08 & 1.92 \\
Ni-added & 0.69 & 0.35 & 0.07 & - & - & bal. & 1.04 & 1.97 \\
Co-added & 0.60 & 0.41 & - & 0.10 & - & bal & 1.01 & 1.46 \\
V-added & 0.71 & 0.33 & - & - & 0.09 & bal. & 1.04 & 2.15
\end{tabular}

\section{Results}

\subsection{Micro Vickers hardness measurement in single-step aged condition}

Figure 1 shows ageing hardening curves of all alloys aged at $473 \mathrm{~K}$. Values of as-quenched in TM- added alloys were higher than that of the base alloy due to solid solution hardening. Ni- and Co- added alloys increase the hardness quickly and shows higher hardness compared with the base alloy in under-aged condition. Every TM-added alloys increase the level of peak hardness remarkably in particular Ni-added alloy. Ni- and Co-added alloys reached peak hardness with shorter ageing time than the base alloy.

\subsection{TEM observation in the peak-aged condition at $473 \mathrm{~K}$}

TEM bright-field images of all alloys in each peak-aged condition are shown in Fig. 2. TEM observation was conducted in the $(100)_{\mathrm{Al}}$ plane. Needle-like precipitates with along to $\langle 100\rangle_{\mathrm{Al}}$ direction and their cross-sections mainly can be seen in those pictures. 


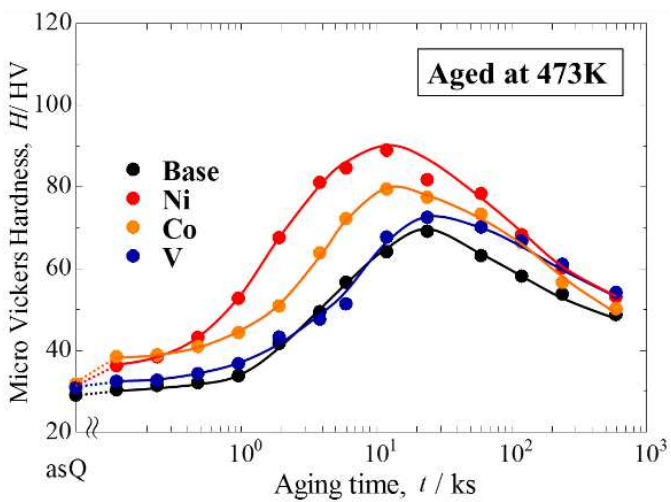

Fig. 1. Hardness changes during ageing at $473 \mathrm{~K}$.
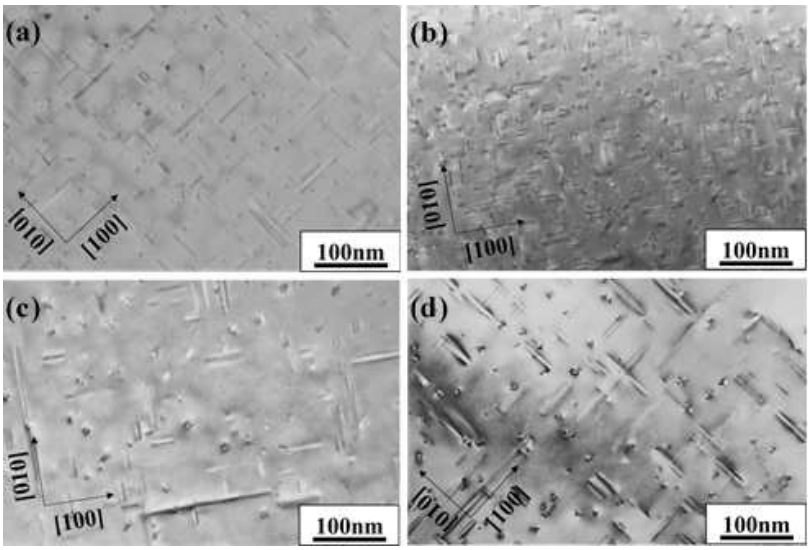

Fig. 2. TEM bright-field images from samples in peakaged condition at $473 \mathrm{~K}$. (a) Base alloy, (b) Ni-added alloy, (c) Co-added alloy, (d) V-added alloy.

Figure 3 shows (a) number density of cross-sectional precipitates and (b) average needle length in all alloys. TM-added alloys showed higher number density and shorter lengths than those of the base alloy. In other words, TM-added alloys had finer distribution of precipitates and we assume that $\mathrm{Ni}, \mathrm{Co}$, and V elements somehow contribute to nucleation.

To investigate further structures of precipitates, we conducted HRTEM observation (Fig. 4). From Fig. 4a$\mathrm{d}$, we found that four type precipitates commonly can be seen in all alloys. According to our previous report [3], random-type precipitate also can be observed in the early stage of ageing and has a disorder structure (Fig. 4a).

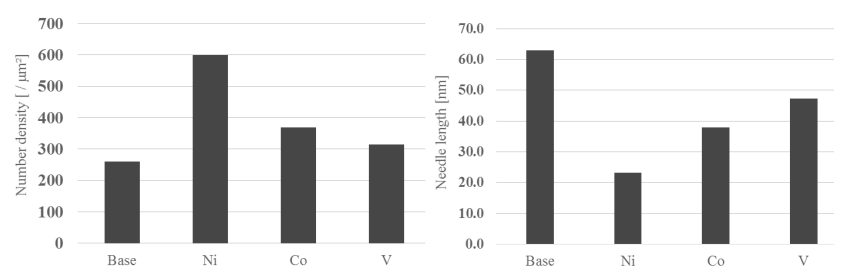

Fig. 3. (a) Number density of cross-sectional precipitates and (b) average length of needle-shape precipitates in all alloys after peak-aged treatment.
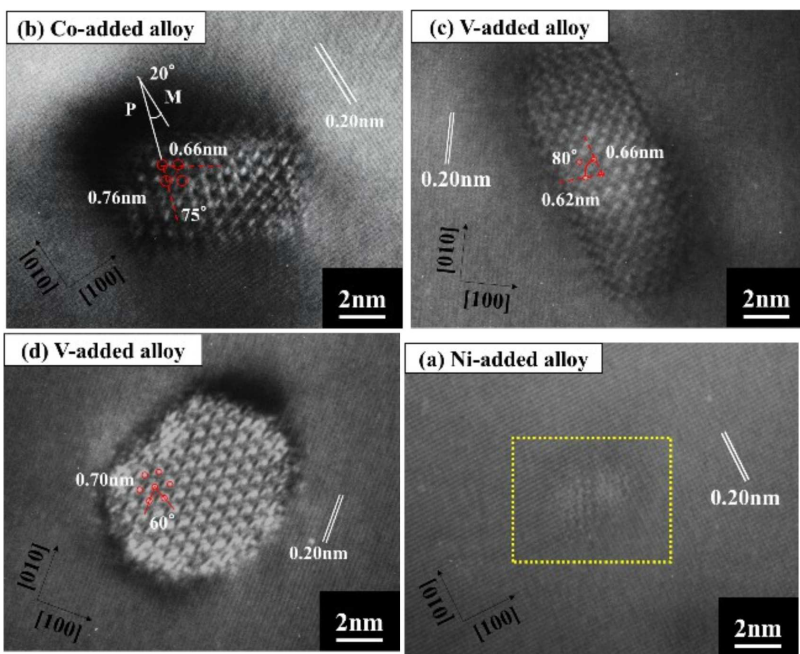

Fig. 4. HRTEM images of precipitates in peak-aged condition at $473 \mathrm{~K}$. (a) Random-type, (b) $\beta^{\prime \prime}$ phase, (c) parallelogram-type, (d) $\beta^{\prime}$ phase.

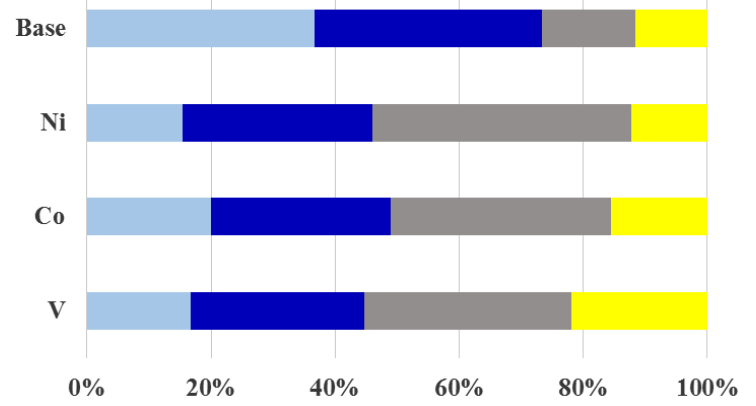

Fig. 5. Relative frequency of the precipitates in each peak-aged condition. random-type parallelogram-type $\beta^{\prime \prime}$ phase $\beta^{\prime}$ phase.

Figure $4 \mathrm{~b}$ shows the precipitate with the parallelogram networks of the bright dots. It has specific its interior angle $\left(\theta=75^{\circ}\right)$ and a lattice parameters $(a=0.77 \mathrm{~nm}$, $b=0.67 \mathrm{~nm})$. This type is called $\beta^{\prime \prime}$ phase. In Fig. 4c, there is parallelogram networks of bright dots similar to $\beta^{\prime \prime}$ phase, however, its interior angle $\theta$ is not fixed to a certain degree but the range of $60^{\circ}<\theta<90^{\circ}$. It can be attributed to the parallelogram-type precipitate. The hexagonal networks of the bright dots of the precipitate are observed in Fig. $4 \mathrm{~d}$ with the spacing about $0.71 \mathrm{~nm}$. It is classified as $\beta^{\prime}$ phase.

Four types of precipitates distribution of each alloy are shown in Fig. 5. We analyzed more than 20 crosssectional precipitates. The distribution of the precipitates for the base alloy has been reported in our previous work. The random-type and parallelogram-type precipitates are observed as the main precipitates in the base alloy [4]. The precipitation sequence for three TM-added alloys are shifted to more stable phases than the base alloy because random-type precipitates are formed between GP zone and parallelogram-type precipitates, $\beta^{\prime \prime}$ or $\beta^{\prime}$ phase according to our previous report $[3,5]$. 


\subsection{Micro Vickers hardness measurement in two-step aged condition}

Figure 6 shows ageing hardening curves of Co-added alloy in single- and two-step aged conditions. In the case of aged at $343 \mathrm{~K}$ for $60 \mathrm{ks} \& 473 \mathrm{~K}$, peak hardness is higher than that of single ageing (positive effect). On the other hand, the peak hardness of aged at $298 \mathrm{~K}$ for $60 \mathrm{ks} \& 473 \mathrm{~K}$ is low compared to that of single-step aged conditions (negative effect).

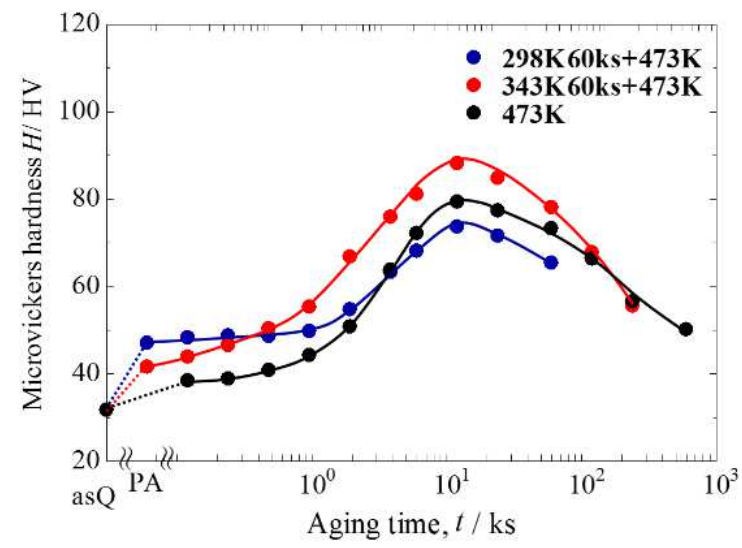

Fig. 6. Ageing hardening curves of Co-added alloy in single- and two-step aged conditions.

\subsection{TEM observation of Co-added alloy in two-step aged conditions}

TEM bright-field images of Co-added alloy in each peak-aged conditions of two-step ageing are shown in Fig. 7.
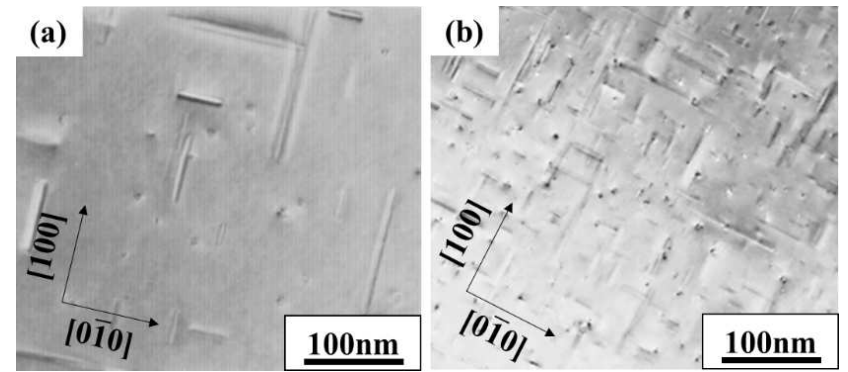

Fig. 7. TEM bright-images of Co added alloy after heat treatment at (a) $298 \mathrm{~K}$ for $60 \mathrm{ks} \& 473 \mathrm{~K}$ for $24 \mathrm{ks}$, (b) $343 \mathrm{~K}$ for $60 \mathrm{ks} \& 473 \mathrm{~K}$ for $12 \mathrm{ks}$.

Figure 8 shows (a) number density of cross-sectional precipitates and (b) average needle length in Co-added

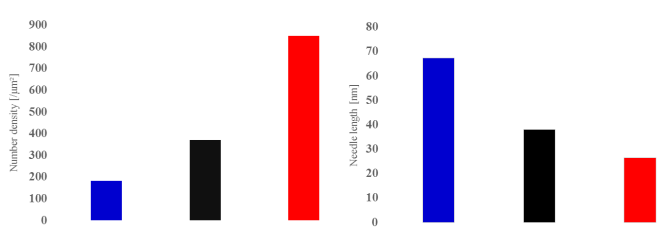

Fig. 8. (a) Number density of precipitates and (b) average length of needle-shape precipitates after heat treatment at $298 \mathrm{~K}$ for $60 \mathrm{ks} \& 473 \mathrm{~K}$ for $24 \mathrm{ks}$ (left), $343 \mathrm{~K}$ for $60 \mathrm{ks} \& 473 \mathrm{~K}$ for $12 \mathrm{ks}$ (middle), and $343 \mathrm{~K}$ for $60 \mathrm{ks} \& 473 \mathrm{~K}$ for $12 \mathrm{ks}$ (right).

alloys in single- and two-step aged conditions. From Fig. 7 and Fig. 8, it can be suggested that higher number density of precipitate are responsible for higher hardness.

\section{Conclusions}

1. As-quenched and peak hardness value of TM-added alloys is higher than that of the base alloy after ageing at $473 \mathrm{~K}$.

2. Ni-added alloy has a highest of peak hardness in all alloys.

3. TM-added alloys have finer distribution of precipitates in TEM observation.

4. Four kinds of precipitates (random-type, parallelogram-type, $\beta^{\prime}$ phase, and $\beta^{\prime \prime}$ phase) has been commonly observed in all of the alloy.

5. Peak hardness of Co-added alloy after ageing at $343 \mathrm{~K}$ for $60 \mathrm{ks} \& 473 \mathrm{~K} 12 \mathrm{ks}$ is higher than that of single-ageing (positive effect). On the other hand, peak hardness of aged at $298 \mathrm{~K}$ for $60 \mathrm{ks} \& 473 \mathrm{~K}$ for $24 \mathrm{ks}$ is lower compared to that of single-step ageing (negative effect).

\section{References}

[1] S. Wang, K. Matsuda, Mater. Trans. 52, 229 (2011).

[2] S. Wang, K. Matsuda, J. Alloys Comp. 509, 9876 (2011).

[3] K. Matsuda, H. Gamada, K. Fujii, Y. Yoshida, T. Sato, A. Kamio, S. Ikeno, J. Jpn. Inst. Light Met. 47, 493 (1997).

[4] S. Ikeno, H. Matsui, K. Matsuda, K. Terayama, Y. Uetani, J. Jpn. Inst. Light Met. 65, 404 (2001).

[5] S. Ikeno, J. Jpn. Inst. Light Met. 63, 318 (2013). 